\title{
Letter \\ The nature of unmeasured anions in critically ill patients
} Miriam AM Moviat, Peter Pickkers, Wim Ruitenbeek and Johannes G van der Hoeven

Department of Intensive Care Medicine, Radboud University Nijmegen Medical Centre, Postbus 9101; 6500 HB Nijmegen, The Netherlands

Corresponding author: Miriam AM Moviat, moviat@inter.nl.net

Published: 22 April 2008

Critical Care 2008, 12:416 (doi:10.1186/cc6855)

This article is online at http://ccforum.com/content/12/2/416

(C) 2008 BioMed Central Ltd

See related commentary by Venkatesh and Morgan, http://ccforum.com/content/12/1/113

We read with interest the commentary of Venkatesh and Morgan in the February issue of Critical Care [1], in which they discuss the continuing need for clarification of the nature of unmeasured anions in critically ill patients. The questions asked in this commentary arise from the study of Bruegger and colleagues in a previous issue of this journal [2]. The main issue discussed is the ongoing uncertainty about the contribution of intermediates of the tricarboxylic acid (TCA) cycle to the strong ion gap (SIG). As Venkatesh and Morgan accurately point out, the extremely high concentrations of acetate and citrate found by Bruegger and colleagues may very well be confounded by the exogenous administration of resuscitation fluids and blood products in the animal model described.

In the March issue of Critical Care Medicine, we published our study conducted in critically ill patients with a metabolic acidosis with and without an increased SIG, representing the absence or presence of unmeasured anions [3]. We explored the presence of and contribution to the SIG of a large variety of compounds, largely organic acids and amino acids, by use of several laboratory techniques such as ion-exchange column chromatography and gas chromatography. In addition, proton nuclear magnetic resonance ( $\left.{ }^{1} \mathrm{H}-\mathrm{NMR}\right)$ spectroscopy was used to quantify intermediates of the TCA cycle. Despite our elaborate attempt, only $7.9 \%$ of the difference in SIG between the low and high SIG groups could be explained by the presence of high concentrations of amino acids, uric acid, and organic acids. As a single compound, uric acid was responsible for the largest relative contribution to the SIG, namely $2.2 \%$.

Our study excludes many other potent unmeasured anions, such as uremic toxins and pyroglutamic acid, as major contributors to the SIG. As to the presence of TCA cycle intermediates, only succinic acid was significantly elevated in the high SIG group but it accounted for only $0.07 \%$ of the increased SIG. Furthermore, concentrations of isocitrate and citrate obtained by gas chromatography were not relevantly elevated in the high SIG group and all intermediates of the TCA cycle quantified with ${ }^{1} \mathrm{H}-\mathrm{NMR}$ spectroscopy, including acetic acid, corresponded to the published reference ranges. As outlined in our discussion, these findings are in contradiction to a recent human study [4]. The accumulation of TCA cycle intermediates by the mechanism of accelerated amino acid catabolism would imply distinct patterns of altered amino acid concentrations, which also was not supported by the results of our study.

Our research enables us to answer the last question posed in the commentary of Venkatesh and Morgan. Raised concentrations of (iso)citrate and acetate do not clarify the SIG in the critically ill. Thus, a significant contribution of TCA cycle intermediates to the SIG in human acidosis is excluded. However, given the small percentage of the SIG that was represented by the measured anions, a largely unclarified portion of the strong anion gap remains to be explored.

\section{Competing interests}

The authors declare that they have no competing interests.

\section{References}

1. Venkatesh B, Morgan TJ: Unmeasured anions: the unknown unknowns. Crit Care 2008, 12:113.

2. Bruegger D, Kemming GI, Jacob M, Meisner FG, Wojtczyk CJ, Packert KB, Keipert PE, Faithfull S, Habler OP, Becker BF, Rehm $\mathrm{M}$ : Causes of metabolic acidosis in canine hemorrhagic shock: role of unmeasured ions. Crit Care 2007, 11:R130.

3. Moviat, MAM, Terpstra AM, Ruitenbeek W, Kluijtmans LAJ, Pickkers P, van der Hoeven JG: Contribution of various metabolites to the "unmeasured" anions in critically ill patients with metabolic acidosis. Crit Care Med 2008, 36:752-758.

4. Forni LG, McKinnon W, Lord GA, Treacher DF, Peron JM, Hilton $\mathrm{PJ}$ : Circulating anions usually associated with the Krebs cycle in patients with metabolic acidosis. Crit Care 2005, 9:R591R595.

${ }^{1} \mathrm{H}-\mathrm{NMR}=$ proton nuclear magnetic resonance; $\mathrm{SIG}=$ strong ion gap; TCA = tricarboxylic acid. 